\title{
(RE)USO DA ÁGUA DA CHUVA: EXPERIÊNCIA NO COLÉGIO POLITÉCNICO DE SANTA MARIA (RS)
}

\author{
Gabriella Eldereti Machado ${ }^{1}$ \\ Natana Pozzer Vestena ${ }^{2}$ \\ Ivanio Folmer ${ }^{3}$
}

Resumo: A água esta disponível de várias formas na natureza, cobrindo aproximadamente $70 \%$ da superfície do planeta, ela é fundamental para a sobrevivência dos seres vivos, pois todos os organismos necessitam da mesma, porém, para sua utilização é essencial que os recursos hídricos estejam em condições físicas e químicas adequadas. Embora seja demonstrada a abundância da água no planeta, nem toda sua totalidade é usada pelo homem. A presente pesquisa foi realizada no Colégio Politécnico da Universidade Federal de Santa Maria, no qual se buscou conhecer as alternativas para o (re)uso da água, criadas e realizadas em diversos setores do local do estudo.

Palavras-chave: Educação Ambiental; (Re)uso da Água da Chuva; Meio Ambiente.

${ }^{1}$ Universidade Federal de Santa Maria (UFSM). E-mail: gabriellaelderete@hotmail.com.

2 Universidade Federal de Santa Maria (UFSM).

3 Universidade Federal de Santa Maria (UFSM).

Revbea, São Paulo, V. 11, № 5: 10-18, 2016. 


\section{Introdução}

A água está disponível de várias formas na natureza, cobrindo aproximadamente $70 \%$ da superfície do planeta, ela é fundamental para a sobrevivência dos seres vivos, pois todos os organismos necessitam da mesma, porém, para sua utilização é essencial que os recursos hídricos estejam em condições físicas e químicas adequadas. Embora seja demonstrada a abundância da água no planeta, nem toda sua totalidade é usada pelo homem. Somente $0,5 \%$ é água doce explorável, que pode ser extraída de lagos, rios e aquíferos, com possibilidade tecnológica e econômica para essa extração.

Sendo assim, é importante a conscientização sobre o uso responsável da água disponível para consumo, já que atualmente tem-se problemas ambientais que interferem no ciclo hidrológico, afetando a disponibilidade de água. Segundo Senac (2009, p.124) "em vista do consumo equivocado, que causa tantos problemas ambientais, sociais e econômicos, governos, empresas, ONGs e outros grupos da sociedade civil começam a buscar o consumo sustentável', uma dessas formas sustentáveis é a (re)utilização da água da chuva. Outra questão importante a se enfatizar, é a qualidade da água, pois dependendo da sua condição, pode ser um agravante para a escassez. A água que utilizamos no cotidiano deve conter algumas exigências sanitárias e toxicológicas adequadas, ser isenta de organismos patogênicos e substâncias tóxicas para não causar danos à saúde.

Para a irrigação, depende do tipo de cultura a ser cultivada e a quantidade de sais, que podem afetar a atividade osmótica da planta, ou interferir o metabolismo das plantas, e no solo causando a redução da permeabilidade dificultando a drenagem.

Para fins energéticos é utilizada na geração de energia, através do vapor de água nas usinas termoelétricas ou aproveitamento de energia potencial ou cinética da água nas usinas hidrelétricas. Nesses casos a qualidade da água não possui um caráter restritivo, somente para a preservação dos equipamentos utilizados. Nessas atividades, o meio ambiente pode ser afetado, no caso os meios aquáticos, devido à montagem de barragens a partir de lagos, alterando o ecossistema.

Devido à proximidade de relações acadêmicas, realizou-se a pesquisa no Colégio Politécnico da Universidade Federal de Santa Maria (UFSM), o qual conta com Cursos em Nível de Ensino Médio, Técnico, Tecnólogo e PósGraduação. O propósito da presente pesquisa é relatar os meios e experimentações projetadas para (re)uso da água da chuva no Colégio Politécnico da UFSM. 


\section{Desenvolvimento}

A presente pesquisa foi realizada no Colégio Politécnico da Universidade Federal de Santa Maria, no qual se buscou conhecer as alternativas para o (re)uso da água, criadas e realizadas em diversos setores do local do estudo.

A água que é utilizada em alguns locais possui origem do subsolo da UFSM, servindo ao consumo humano, descargas de sanitário e limpezas das edificações e do maquinário. Portanto, neste local, torna-se importante a preservação dos recursos naturais para diminuição e cuidado com o consumo das águas do subsolo, levando a um caminho de preservação do meio ambiente e promovendo a conscientização ambiental dos seus alunos, funcionários e comunidade em geral. Segundo Filipetto (2005) é necessário investimentos em "ações permanentes de conservação e uso racional deste recurso que está se tornando caro e difícil. Principalmente para o meio rural que demanda uma grande quantidade de água potável para irrigação e criações animais" (FILIPETTO, 2005, p. 56).

Dessa forma, pesquisou-se sobre as atividades que foram desenvolvidas, no qual pode ser mencionado o aproveitamento de água da chuva para lavagem de máquinas e para irrigação do ambiente climatizado da floricultura; melhorias no aproveitamento de água da chuva: construção de filtro de sólidos grosseiro de baixo custo. A coleta de água de chuva ocorre em áreas impermeáveis, normalmente o telhado.

O processo de coleta d'água inicia com a água que cai no telhado, lavando o espaço de contato inicial, que apresenta um grau de contaminação bastante elevado e, por isso, é aconselhável o desprezo desta primeira água. A água de chuva coletada através de calhas, condutores verticais e horizontais é armazenada em reservatório, que pode ser de diferentes materiais. Essa água deverá ser utilizada somente para consumo não potável, como em irrigação de jardins, pomares e para lavagem de máquinas agrícolas.

Assim, cada vez mais vem se tornando fundamental a conscientização da população sobre o uso racional da água e a necessidade de implantação de um sistema de abastecimento de água seletivo. Muitas vezes a água potável é utilizada para a realização de todas as atividades, independentemente do uso ao qual se destina.

\section{Contribuições da Educação Ambiental para a conscientização para o uso sustentável da água:}

Através da perspectiva da educação ambiental, entendo-a como um direito e dever de todos, se fazendo presente em discussões e conteúdos na educação básica, correspondendo como um tema transversal, que possibilita ser abordada em diversos componentes curriculares e nos Projetos Políticos Pedagógicos das escolas. Os direitos para a inserção da educação ambiental 
no contexto escolar e da sociedade estão assegurados pela Lei n. 9.795 de 1999, que a institui na Política Nacional de Educação Ambiental.

Prevendo que a educação ambiental nas instituições de ensino, tenha que contemplar: abordagem curricular que enfatize a natureza como fonte de vida e relacione a dimensão ambiental à justiça social, aos direitos humanos, à saúde, ao trabalho, ao consumo, à pluralidade étnica, racial, de gênero, de diversidade sexual, e à superação do racismo e de todas as formas de discriminação e de injustiça social (Resolução n. 2, de 15 de junho de 2012: capítulo II, art. 14, parágrafo I que trata dos objetivos da educação ambiental).

Por este fato, torna-se relevante o processo de conscientização, relacionando com o conhecimento do cotidiano, e através das vivências das pessoas proporem mudanças à realidade. O processo de conscientização acontece principalmente no ensino formal, através de educadores e educandos no espaço escolar, por meio do diálogo em torno da realidade da comunidade em que a escola está situada, afim de uma construção de alternativas para melhores condições de vida no lugar onde vivem. Nesse sentido de conscientização e busca por uma educação pelo diálogo e de cunho cidadão, inspira-se em Paulo Freire, que menciona sobre o conhecimento de uma forma construída pelo aluno em comunhão com o professor, e não na forma de depósito de conteúdos, relacionando o ensino como um processo de aprendizado de vivências práticas.

Pelo caminho do exercício permanente de do pensamento crítico, aprimorando a aprendizagem pela conscientização e realização de experiências. O ideal para ter-se uma conscientização através da educação ambiental, é que seja um processo organizado de forma interdisciplinar, que integre os temas nos currículos das diversas áreas do conhecimento.

No âmbito dos poderes públicos, a implantação de programas de educação ambiental, tem o objetivo de estimular um fluxo de trocas de informações, para permitir contribuições e trocas de ideias e informações entre as pessoas. Assemelha-se com a escola no fato de relacionar as questões nacionais e globais com as situações do cotidiano, trazendo experiências vividas. Neste contexto, realiza-se em nível mundial alguns congressos e eventos que preveem a garantia dos cuidados e preservação do meio ambiente, assim como a educação ambiental, um dele é a carta de Belgrado.

Esta carta buscou uma estrutura global para a educação ambiental, elaborada no final do encontro em Belgrado, lugoslávia, em 1975, promovido pela UNESCO, tornando-se um marco para o debate de questões ambientais. Prevê os seguintes tópicos:

1. Conscientização: contribuir para que indivíduos e grupos adquiram consciência e sensibilidade em relação ao meio ambiente como um todo e quanto aos problemas relacionados com ele.

2. Conhecimento: propiciar uma compreensão básica sobre o meio ambiente, principalmente quanto às influências do ser humano e de suas atividades. 
3. Atitudes: propiciar a aquisição de valores e motivação para induzir uma participação ativa na proteção ao meio ambiente e na resolução dos problemas ambientais.

4. Habilidades: proporcionar condições para que os indivíduos e grupos sociais adquiram as habilidades necessárias a essa participação ativa.

5. Capacidade de avaliação: estimular a avaliação das providências efetivamente tomadas em relação ao meio ambiente e aos programas de educação ambiental.

6. Participação: contribuir para que os indivíduos e grupos desenvolvam o senso de responsabilidade e de urgência com relação às questões ambientais.

Outro documento importante no cenário mundial é a Agenda 21, que foi aprovado durante a Conferência do Rio de Janeiro em 1992. Ela é constituída por 40 capítulos, onde estão os seguintes: 1 . às diversas questões sociais e ambientais de caráter planetário; 2. ao fortalecimento das ONGs, governos locais, comunidade científica e tecnológica, sindicatos, indústria e comércio etc.; 3. aos meios de implementação, como mecanismos financeiros, desenvolvimento científico e tecnológico, cooperação internacional e a promoção do ensino.

Esses documentos ajudam a fortalecer a importância da educação ambiental e o processo educativo no qual o sujeito vai se percebendo como transformador da realidade, um ser político devido sua presença no mundo, que pode participar ativamente de decisões em vista da defesa dos diversos espaços socioambientais do seu cotidiano. Paulo Freire reflete que educar se torna um ato de reflexão construtiva do conhecimento, pró formando cidadãos politizados para com a realidade do mundo, em meio a um conhecimento pelo viés libertador, um conhecimento problematizado e referenciado.

Assim incentiva uma educação ambiental comprometida com a formação integral do aluno, e a relevância da conscientização política e a formação ética da responsabilidade para com os outros e com o Planeta tornase importante. Assumindo que as mudanças e transformações do mundo e os processos de ensino e aprendizagem se relacionam com momentos de açãoreflexão na prática educativa.

O governo Brasileiro possui diversos programas na área ambiental, para a conservação e preservação da água tem o programa intitulado Água Doce. Que abrange a ação do Governo Federal coordenada pelo Ministério do Meio Ambiente, por meio da Secretaria de Recursos Hídricos e Ambiente Urbano, em parceria com instituições federais, estaduais, municipais e sociedade civil.

Visando que se firme e estabeleça uma política pública permanente de acesso à água de boa qualidade para o consumo humano, promovendo e disciplinando a implantação, a recuperação e a gestão de sistemas de dessalinização ambiental e socialmente sustentáveis para atender, 
prioritariamente, as populações de baixa renda em comunidades difusas do semiárido.

Embora o programa tenha sido lançado em 2004, ele possui sua concepção e elaboração de forma participativa no ano de 2003, onde uniu a participação social, proteção ambiental, envolvimento institucional e gestão comunitária local. Estrutura-se em seis componentes: gestão, pesquisa, sistemas de dessalinização, sustentabilidade ambiental, mobilização social e sistemas de produção.

\section{Consumo sustentável: $O$ que podemos aprender para modificar?}

Segundo a Agenda 21 Global, em seu Capítulo 4, que dispõe sobre a relevância em se atentar para o consumo como "culpado" de diferentes impactos ambientais e sociais. Então o Consumo Sustentável engloba a escolha de produtos que utilizam menos recursos naturais em sua produção, que garantiram o emprego decente aos que os produziram, e que serão facilmente reaproveitados ou reciclados.

Ou seja, é um processo de conscientização para se comprar aquilo que é realmente necessário, estendendo a vida útil dos produtos tanto quanto possível. Para que possamos consumir de maneira sustentável, no momento em que nossas escolhas de compra são conscientes, responsáveis, com a compreensão de que terão consequências ambientais e sociais.

Mas o que fazer para modificar e mudar o contexto em que vivemos? Podemos partir justamente da mudança, repensando o comportamento, nos dispondo a observamos os valores de sustentabilidade e justiça social, para fazer parte da consciência coletiva. E a partir do consumo consciente, a sociedade vai se modificando e reduzindo significativamente os impactos negativos no acumulado do consumo de todos os cidadãos.

\section{Resultados Obtidos}

A partir de cada trabalho pesquisado no Colégio Politécnico da UFSM, foram selecionados e analisados dois destes, apresentados seus resultados a seguir:

\section{Aproveitamento de água da chuva para lavagem de máquinas e irrigação do ambiente climatizado da floricultura}

Os sistemas de aproveitamento da água da chuva são utilizados desde a história antiga, com cisternas de armazenamento d'água para o consumo humano, embora atualmente as águas destinadas para o consumo humano necessitem de tratamento específico. As águas coletadas foram utilizadas para outros fins como limpezas, irrigações e lavagens, que podem ter origem das águas da chuva. 
O recolhimento da água da chuva possibilitou o uso para diversos fins, diminuindo a utilização da água do subsolo e contribuindo na preservação do meio ambiente, evitando o assoreamento dos rios. Fato que se alia ao elevado consumo de água para fins de lavagem das máquinas agrícolas usadas nas lavouras, e ao mesmo tempo, o Colégio possui várias edificações de um pavimento com grandes áreas de cobertura que poderiam ser utilizadas para a captação da água da chuva.

$\mathrm{Na}$ execução do projeto foi calculada a área do telhado da garagem juntamente com o comprimento das calhas e o volume das caixas d'água receptoras. Posteriormente, foi feito um levantamento da precipitação pluviométrica da cidade de Santa Maria, para ter uma ideia de quanto o telhado captará. Para tal, os alunos se basearam em uma revisão de literatura a respeito da utilização das águas da chuva para fins de irrigação em estufas. Em outro momento, esta revisão serviu de base para o cálculo de dimensionamento das calhas e reservatórios das águas. Este cálculo considerou a precipitação média local e a característica do telhado da estufa. Também nesta análise foi avaliado o custo de toda a instalação.

Portanto, fez-se uma relação entre o volume utilizado para a lavagem de máquinas do Colégio e a tarifa mensal que seria paga à CORSAN, caso fosse usada água tratada. Nos cinco meses em que o projeto foi desenvolvido, foram arrecadados 88.936 litros de água da chuva. Dividindo este volume pelo número de meses em questão, a média mensal de água coletada foi de 17.787 litros. Como a capacidade de armazenamento era de apenas 21.000 litros, e houve meses em que a coleta ultrapassou esse número, como julho e agosto, adicionaram mais duas caixas d'água para o armazenamento da coleta excedente, sendo que cada caixa d'água tem capacidade de 7.000 litros.

Os litros que, em alguns meses, não foram utilizados para a lavagem das máquinas, foram destinados à irrigação do pomar e à limpeza do Colégio. Para a lavagem das máquinas, são gastas 5 horas semanais com o auxílio de uma lavadora hídrica com vazão de $900 \mathrm{~L} / \mathrm{h}$; assim, gastou-se 18.000 litros por mês. A tarifa básica de água da CORSAN é de $R \$ 3,90$ por 1.000 litros, então, multiplicando o volume de água utilizada por mês com a tarifa, obteve-se uma economia mensal de $R \$ 70,20$. Em cinco meses, a economia foi de $R \$ 351,00$.

\section{Melhorias no aproveitamento de água da chuva: construção de filtro de sólidos grosseiro de baixo custo}

O filtro para descarte de sólidos grosseiros foi construído nas instalações do Colégio Politécnico da UFSM, no setor de Energias Alternativas e Hidráulica, o Colégio possui sistemas de coleta de água da chuva direto (calhas, condutores e cisternas), onde em algumas cisternas existem problemas devido a grande quantidade de matéria orgânica que ficam contidas nestas. Para construção do filtro, utilizaram um galão de 20 litros, tela, cano PVC, além de cola silicone, parafusos e ferramentas de corte. 
O filtro funciona basicamente desta forma: a água da chuva com folhas e outros detritos, quem vem através dos condutores, caem sobre o galão o qual possui uma tela inclinada, no final da inclinação desta tela tem-se uma abertura para a saída de folhas, a água que passa a tela é direcionada até a cisterna.

A utilização do filtro se mostrou eficiente impedindo que as folhas entrassem na cisterna após as chuvas. As chuvas com maiores intensidades permitiam melhor limpeza na tela inclinada do filtro, mas mesmo assim não foram necessárias manutenções. O custo do filtro ficou em torno de 35,00 reais, comparando com os filtros convencionais, os quais dependendo do modelo, variam de 250,00 reais chegando até 1.800 reais.

\section{Conclusão}

A água é o elemento essencial para a vida, mas possui suas limitações e pode acabar se não a usarmos de uma forma sustentável e responsável. A pesquisa resultou em aprendizagens sobre formas acessíveis e criativas para a utilização da água da chuva, que geralmente é descartada e não usada para atividades que aceitam essa substância fornecida pela natureza.

Ressaltasse assim, a finalidade principal desses projetos, que é a conscientização ambiental e não somente a economia financeira, por ser tratar de uma instituição educacional que desenvolve, em seu âmbito, a conscientização ambiental e difunde desse modo, a ideia de desenvolvimento sustentável.

Torna-se evidente, portanto que, as alternativas para soluções sustentáveis e ambientalmente corretas estejam em evidência em diversas pesquisas em relação a utilização da água da chuva, que é uma iniciativa criativa e próspera. Sem desconsiderar assim, suas vantagens, destacando a redução do consumo de água potável, e desvantagem como a limitação em suas utilizações, dependendo da quantidade de chuva, área de captação dos telhados e armazenamento em cisterna, fatos que devem ser aprimorados.

\section{Referências}

FILIPETTO, J.E. Conservação da água, um desafio para o meio rural. In: 0 ambiente em debate na UFSM: a contribuição das diversas áreas do saber humano. SOUZA, S.E.R.; et al. (Org.). Santa Maria: Ed. Da UFSM, 2005.

FREIRE, P. Conscientização: teoria e prática da libertação - uma introdução ao pensamento de Paulo Freire. 3. ed. São Paulo: Moraes, 1980. 102 p.

FREIRE, P. Educação como prática da liberdade. 17. ed. Rio de Janeiro: Paz e Terra, 1983. 150 p.

FREIRE, P. Pedagogia da autonomia. Rio de Janeiro: Paz e Terra; Anca/MST, 2004. 143 p. 
FREIRE, P. Pedagogia do oprimido. 37. ed. Rio de Janeiro: Paz e Terra, 2003. $184 \mathrm{p}$.

Introdução à engenharia ambiental. - 2a․ Ed. vários autores. São Paulo: Pearson Prentice Hall, 2005.

Lei n. 9.795 de 1999, Política Nacional de Educação Ambiental (PNEA), MINISTÉRIO DA EDUCAÇÃO CONSELHO NACIONAL DE EDUCAÇÃO. Resolução n. 2, de 15 de Junho de 2012. DOU de 18/06/2012 (n. 116, Seção 1, Pág. 70). Estabelece as Diretrizes Curriculares Nacionais para a Educação Ambiental.

MAY, S. Estudo da viabilidade do aproveitamento de água de chuva para consumo não-potável em edificações. 2004. Dissertação (Mestrado em Engenharia de Construção Civil e Urbana) - Escola Politécnica da Universidade de São Paulo, São Paulo. 2004.

Ministério do Meio Ambiente. Água doce. Disponível em: http://www.mma.gov.br/agua/agua-doce, acesso em: 30/06/2015

SENAC. D.N. Uso sustentável do meio ambiente. In: CARNEIRO, R.; ABAURRE, N.W.; SERRÃO, M.A. (Org). Transversalidade e inclusão: desafios para o educador. Rio de Janeiro: Senac Nacional, 2009. 